\title{
Novel multiple opioid ligands based on 4-aminobenzazepinone (Aba), azepinoindole (Aia) and tetrahydroisoquinoline (Tic) scaffolds
}

\author{
Steven Ballet ${ }^{a, b}$, Ewa D. Marczak ${ }^{C}$, Debby Feytens ${ }^{a}$, Severo Salvadorid, Yusuke Sasaki ${ }^{\mathrm{e}}$, \\ Andrew D. Abell ${ }^{b}$, Lawrence H. Lazarus ${ }^{C}$, Gianfranco Balboni ${ }^{f}$, and Dirk Tourwéa \\ a Department of Organic Chemistry, Vrije Universiteit Brussel, B-1050 Brussels, Belgium \\ b School of Chemistry and Physics, University of Adelaide, 5005 SA, Australia \\ c Medicinal Chemistry Group, LP, National Institute of Environmental Health Sciences, North \\ Carolina, 27709, U.S.A. \\ d Department of Pharmaceutical Sciences and Biotechnology Center, University of Ferrara, I-44100 \\ Ferrara, Italy \\ e Department of Pharmacology, Tohoku Pharmaceutical University, 4-1 Komatsushima 4-chome. \\ Aobe-Ku, Sendai 981-8558, Japan \\ f Department of Toxicology, University of Cagliari, I-09124, Cagliari, Italy
}

\section{Abstract}

The dimerization and trimerization of the Dmt-Tic, Dmt-Aia and Dmt-Aba pharmacophores provided multiple ligands which were evaluated in vitro for opioid receptor binding and functional activity. Whereas the Tic- and Aba multimers proved to be dual and balanced $\delta / \mu$ antagonists, as determined by the functional $\left[\mathrm{S}^{35}\right] \mathrm{GTP} \gamma \mathrm{S}$ binding assay, the dimerization of potent Aia-based 'parent' ligands unexpectedly resulted in substantial less efficient receptor binding and non-active dimeric compounds.

The beneficial analgesic effect of common opioid ligands such as morphine or fentanyl is accompanied by side-effects on chronic administration. Therefore, significant effort has gone into designing synthetic opioid ligands that selectively interact with the three recognized $\mu-$, $\delta$ - and $\kappa$-subtype opioid receptors. Recently, various peptidic and non-peptidic dimers have been prepared to improve the pharmacological properties of known opioid ligands. ${ }^{1,2} \mathrm{~A}$ general representation of such homo- $\left(\mathbf{1}, \mathrm{P}=\mathrm{P}^{\prime}\right)$ or heterobifunctional $\left(\mathbf{1}, \mathrm{P} \neq \mathrm{P}^{\prime}\right)$ ligands, possessing linkers of variable length, is shown in Figure 1.

Designed multiple ligands (DMLs) of opioid agonists include: peptidic dimers [e.g. enkephalin-based Biphalin 2, ${ }^{3-7}$ endomorphin analogs ${ }^{8}$ and dermorphin-like structures, ${ }^{9}$ nonpeptidic DMLs (e.g. oxymorphone-derived pharmacophores ${ }^{10-13}$ ) and combined peptidicnonpeptidic bifunctional ligands (e.g. enkephalin-analogs linked to a fentanyl unit (e.g.

(C) 2010 Elsevier Ltd. All rights reserved.

Publisher's Disclaimer: This is a PDF file of an unedited manuscript that has been accepted for publication. As a service to our customers we are providing this early version of the manuscript. The manuscript will undergo copyediting, typesetting, and review of the resulting proof before it is published in its final citable form. Please note that during the production process errors may be discovered which could affect the content, and all legal disclaimers that apply to the journal pertain.

Supplementary material Experimental procedures, HPLC and high resolution mass spectrometry data are available. 
structure 3)]. ${ }^{14,15}$ In specific cases, improved pharmacodynamic and pharmacokinetic properties like enhanced affinity, increased activity, relative to 'the golden standard' morphine, and high metabolic stability were observed. ${ }^{3,6}$ The design rationale behind ligands of type $\mathbf{3}$, was based on conjugation of the peptidic sequence to a fentanyl moiety in order to overcome the poor general bioavailability of opioid peptides. Relative to the reference peptide Dmt-DAlaGly-Phe- $\mathrm{NH}_{2}$ the targeted improved $\delta$-receptor affinity was obtained, a goal that finds its roots in the therapeutic advantages of compounds combining both $\mu$ - and $\delta$-opioid agonism over drugs which act solely as agonists at the $\mu$-opioid receptor. ${ }^{16-18}$

Similarly to compounds with a dual $\mu / \delta$ agonist profile, an attenuation of dependency and tolerance to opiates is seen with $\delta$ antagonists ${ }^{16}$ or neutral $\mu$ antagonists. ${ }^{19}$ Because of these therapeutic advantages, Schiller and coworkers successfully prepared chimeric compound 4 with mixed $\mu$ opioid agonist/ $\delta$ opioid antagonist profile in order to obtain a bifunctional structure with analgesic effect and low propensity to induce analgesic tolerance and physical dependence. ${ }^{1,20}$ Chimeric structure $\mathbf{4}$ combines the $\mu$-opioid agonist effect of [Dmt ${ }^{1}$ ]DALDA (Figure 1) with the potent and selective $\delta$-antagonist (inverse $\delta$ agonist) TICP[ $\psi]$ ( $\mathrm{H}-\mathrm{Tyr}-$ Tic $\psi\left[\mathrm{CH}_{2} \mathrm{NH}\right]$ Cha-Phe-OH).

In previous work, structures 5 to $\mathbf{8}$ (Figure 2) were reported to be potent opioid ligands. ${ }^{21,22}$ Beside the $\delta$-selective antagonist Dmt-Tic 5, compounds of type $\mathbf{6}$ and $\mathbf{7}$ displayed full $\mu$ agonist activities, with potencies comparable to endogenous opioid peptides like endomorphin-1 and -2. $N, N$-dimethylation proved to be crucial for the $\delta$-antagonist properties of structure 8. Structure 8 antagonizes the effect of Deltorphin $\mathrm{C}$ in vitro with a potency in the same range as Dmt-Tic $5\left(\mathrm{pA}_{2}{ }^{\delta}(\mathbf{5}): 8.48\right.$ vs. $\left.\mathrm{pA}_{2}{ }^{\delta}(\mathbf{8}): 8.30\right) .{ }^{22}$

This work discusses the preparation and biological evaluation of symmetric dimeric and trimeric peptidomimetic opioid ligands based on opioid scaffolds 5 to 8 . The designed ligands contain compact linkers, that only allow binding in a monovalent mode. ${ }^{1}$ Earlier work of Li et al., involving the linkage of Dmt-Tic 5 by means of diaminoalkyl chains of variable length, resulted in dimeric ligands with increased $\delta$-antagonist potency. ${ }^{23}$ The $\delta$-antagonism potency was improved by two to three orders of magnitude relative to the monomer Dmt-Tic-OH $\left(\mathrm{pA}_{2}\right.$ values between 10.42 and 11.28 vs. 8.48 for Dmt-Tic-OH $){ }^{23}$ The reported dimers represented the most potent in vitro $\delta$-opioid antagonists reported in the literature. ${ }^{23}$ The linker length in these ligands was shown to be of no importance for $\delta$-antagonism, and the observed increase in potency was suggested to be due to a high concentration of the pharmacophore in the vicinity of the recognition site. ${ }^{24}$ In contrast with its more extended analogues, the compact diaminobutane linked dimer butylene-bis[Dmt-Tic-NH] possesses dual, but not balanced, $\delta$ and $\mu$-antagonism $\left(\mathrm{pA}_{2}{ }^{\delta}=10.51\right.$ and $\left.\mathrm{pA}_{2}{ }^{\mu}=6.99\right) .{ }^{23}$ In general, peptidic bifunctional opioid ligands seem to be more active at MOR when the pharmacophores are connected by short linkers. ${ }^{3,5,9}$ Because of this general trend, and in order to obtain a more balanced dual $\mu / \delta$ antagonist, we first opted for the ethylene diamine linker, to give dimer 9 (Figure 2). The monomers for the ethylene diamine-linked dimers 9 to 12 were prepared according to literature procedures, ${ }^{25,26,22}$ followed by standard peptide coupling and deprotection steps (Figure 2). Ethylene diamine or tris(2-aminoethyl)amine were coupled to the building blocks $\mathbf{5}$ to $\mathbf{8}$ by means of PyBOP in the presence of DIPEA. ${ }^{23}$ The $N$-terminal Boc-group was removed from the crude intermediates by acidolysis (TFA/DCM/water 49:49:2), followed by RP-HPLC purification.

The affinities for the MOR and DOR were measured in equilibrium binding assays in rat brain membranes by displacement of $\left[{ }^{3} \mathrm{H}\right] \mathrm{DAMGO}$ and $\left[{ }^{3} \mathrm{H}\right]$ deltorphin-II respectively (Table 1 ). Functional bioactivity was determined in guinea pig ileum (GPI) for $\mu$-opioid receptors and in mouse vas deferens (MVD) for $\delta$-opioid receptors. Moreover, the effect on Loperamide or 
deltorphin C stimulated GTP $\gamma$ S binding in SK-N-SH and NG108-15 cells, respectively, was determined.

Next to the expected low nanomolar affinity and typical Tic-related $\delta$-opioid receptor selectivity values of $\mathbf{9}\left(\mathrm{K}_{\mathrm{i}}^{\delta} 0.96 \mathrm{nM}\right.$ and $\mathrm{K}_{\mathrm{i}}{ }^{\mu} 10.20 \mathrm{nM}$, Table 1$)$, the activity pattern of this dimeric ligand confirms the expected $\delta$-opioid receptor antagonism. In addition, dimer 9 blocks efficiently the effect of the MOR selective agonist Loperamide in an equipotent manner as compared to blockage of the agonist effect of Deltorphin $\mathrm{C}$ at the $\delta$-opioid receptor $\left(\mathrm{pA}_{2}{ }^{\mu}{ }^{9} .03\right.$ vs. $\mathrm{pA}_{2}{ }^{\delta} 9.04$, See Figure 3 ). This confirms that more balanced $\mu / \delta$-antagonism is obtained by shorter linkers than for the longer (e.g. diaminobutane) linkers used by Li. ${ }^{23}$

The dimerization of the $\mu$-selective Dmt-Aba-Gly peptidomimetic $6\left(\mathrm{~K}_{\mathrm{i}}^{\mu} 0.46 \mathrm{nM}\right.$, GPI(IC $\left.{ }_{50}\right)$ $51 \mathrm{nM})^{21}$ led to bifunctional structure 10. This ethylene diamine-linked Dmt-Aba-Gly dimer preserves its $\mu$-selective binding character $\left(K_{i}^{\delta} / K_{i}^{\mu}=9.5\right)$, although with decreased binding affinities. Unexpectedly however, the agonist properties of reference compound $\mathbf{6}$ are converted into an antagonist profile with a potency at $\mathrm{MOR}\left(\mathrm{pA}_{2}{ }^{\mu} 8.54\right)$ and $\mathrm{DOR}\left(\mathrm{pA}_{2}{ }^{\delta} 7.74\right)$ that is lower than those for dimer $\mathbf{9}$. This indicates that activity or efficacy can change upon introduction of the parent compound into bifunctional constructs.

Dimerization of the monomeric ligand $\mathbf{7}^{22}$ to the corresponding dimer 11 (Figure 2) surprisingly resulted in a substantially decreased binding affinity $\left(\mathrm{K}_{\mathrm{i}}{ }^{\mathrm{\mu}}(\mathbf{7}) 3.35 \mathrm{nM}\right.$ vs. $\mathrm{K}_{\mathrm{i}}{ }^{\mu}(\mathbf{1 1})$ $138.7 \mathrm{nM})$. Moreover, the receptor selectivity of $7\left(K_{\mathrm{i}}^{\delta} / K_{\mathrm{i}}^{\mu}=48\right)$ was almost completely lost in $11\left(K_{\mathrm{i}}^{\delta} / K_{\mathrm{i}}^{\mu}=1.5\right)$ This observation was unexpected and, to the best of our knowledge, unprecedented. Literature shows only examples in which dimeric opioid compounds retain or ameliorate the monomer potency upon 'tail-to-tail' dimerization (i.e. C-termini coupled to each other). ${ }^{2}$ Dimer 11 was unable to diminish the GTP $\gamma \mathrm{S}$ binding induced by Loperamide and Deltorphin C (data not shown), proving that in contrast to $\mathbf{1 0}, \mathbf{1 1}$ does not act as an antagonist at MOR and DOR. A similar result was obtained for 12, the dimer of the potent and selective monomer ligand $\mathbf{8}$. The affinity at DOR was strongly decreased upon dimerization of $\mathbf{8}$ $\left(\mathrm{K}_{\mathrm{i}}^{\delta}(\mathbf{8}) 6.64 \mathrm{nM} \rightarrow \mathrm{K}_{\mathrm{i}}^{\delta}(\mathbf{1 2}) 101 \mathrm{nM}\right)$. The loss of $\delta$-receptor selectivity in $\mathbf{1 2}\left(K_{\mathrm{i}}^{\mu} / K_{\mathrm{i}}^{\delta}(\mathbf{8})=\rightarrow\right.$ $\left(K_{\mathrm{i}}^{\mu} / K_{\mathrm{i}}^{\delta}(\mathbf{1 2})=3.4\right)$ can be readily explained by the absence of the C-terminal free carboxyl group, a structural feature that is present in $\mathbf{8}$ and is known to induce $\delta$-receptor selectivity. 20,33

An attempt to recover the activity of the monomeric parent ligand 7 was investigated by adding the "address" part or C-terminal part of ligand 7 consisting of a benzyl moiety. Coupling of Boc-Dmt-D-Aia-Gly-OH to ( $p$-xylylene)bis amine and subsequent acidolysis gave DML 13. Unfortunately, the presence of this aromatic group within the spacer did not improve binding $\left(\left(\mathrm{K}_{\mathrm{i}}^{\mu}{ }^{\mu}(\mathbf{1 3}) 176 \mathrm{nM}\right.\right.$ and $\left.\mathrm{K}_{\mathrm{i}}^{\delta}(\mathbf{1 3}) 360 \mathrm{nM}\right)$, nor functional activity with respect to dimer $\mathbf{1 1}$. These Aia-containing compounds bind to MOR and DOR, albeit with high nanomolar values, but do not display either agonist or antagonist activity. Clearly, the presence of a second Aia-based pharmacophore is detrimental for opioid affinity and activity.

The nature of the linker in various multiple ligands has often been shown to be of importance via its role in hydrophilic/hydrophobic balance, ${ }^{34}$ membrane permeability ${ }^{35}$ and rigidity. ${ }^{13}$ Compound 14 was prepared using a recently introduced methodology which allows the synthesis of dimers of biologically active pharmacophores by means of cross metathesis (CM). ${ }^{36}$ The versatile introduction of the olefin containing tether and subsequent $\mathrm{CM}$ reaction gave readily access to 3,4-ene-hexylenebis[Boc-Tic-NH] $\mathbf{1 8}$ (Figure 2) which was further transformed into 14 according to a standard deprotection/coupling procedure. Ligand 14 displayed sub- to low nanomolar DOR and MOR binding affinity respectively. Previously, the saturated equivalent of 14, 1,6-bis[H-Dmt-Tic-NH]hexane, was determined to be a weak $\mu$ agonist $\left(\mathrm{GPI}\left(\mathrm{IC}_{50}\right) 2715 \mathrm{nM}\right)$ and potent $\delta$-antagonist $\left(\mathrm{pA}_{2}{ }^{\delta} 10.62\right) .{ }^{23}$ In contrast to this 
saturated analogue, olefin-linked $\mathbf{1 4}$ is a potent dual, and balanced, $\delta / \mu$ antagonist as proven by the rightward shift of dose-response curves of deltorphin $\mathrm{C}$ and Loperamide, respectively (supplementary material). Relative to the ethylene linked dimer $\mathbf{9}, \mathbf{1 4}$ shows improved $\mathrm{K}_{\mathrm{i}^{-}}$ values, which are howver not translated into higher antagonist potencies (Table 1). The discrepancy between binding and functional activity is commonly observed with opioid ligands containing the Dmt-Tic scaffold. ${ }^{27,28}$

With the aim of increasing the concentration of the DmtTic pharmacophore 5 at the receptor recognition sites, we prepared trifunctional ligand $\mathbf{1 5}$, derived from tris(2-aminoethyl)amine. The low nanomolar affinity as well as the balanced antagonism of trimer $\mathbf{1 5}$ showed that this compound indeed has the expected profile, although the antagonist activity decreased by one to two orders of magnitude, relative to dimers of type 9 and 14, respectively. Finally, trifunctional structure $\mathbf{1 6}$ was prepared and evaluated. The small loss in $\delta$-binding in respect to dimer 10, combined with a gain in $\mu$-affinity, resulted in enhanced $\mu$-receptor selectivity $\left(K_{i}^{\delta} / K_{i}^{\mu}=24\right)$. The improved binding to MOR was unfortunately not translated in effective functional activity. Only moderate $\mu$-antagonism $\left(\mathrm{pA}_{2}^{\mu}=6.95\right)$ was observed for $\mathbf{1 6}$, indicating that both dimerization and trimerization of the $\mu$-selective agonist scaffold 6 leads to limited $\mu$-antagonism. The results for trimers $\mathbf{1 5}$ and $\mathbf{1 6}$ indicated that no improvement in opioid receptor binding and functional activity was obtained by augmenting the pharmacophore density within vicinity of the opioid recognition sites in these trifunctional compounds.

In conclusion, interesting results were obtained for the activity profile of the discussed bi- or trifunctional ligands, obtained by cross-linking different types of peptidomimetic opioid ligands. The compact ethylene-linked Dmt-Tic dimer 9 shows a more balanced dual antagonist character than those reported for dimers using longer linkers, ${ }^{23}$ in agreement with the design principle. Its potency is slightly lower than that reported for the butylene-bis(Dmt-Tic), in a different assay however.

This study also indicated that dimerization of potent opioid ligands can lead to a loss of affinity, as observed for dimerization of $\mathbf{7}$ to $\mathbf{1 1}$ and of $\mathbf{8}$ to $\mathbf{1 2}$, but also to changes is selectivity and in the conversion of an agonist into an antagonist $(\mathbf{6} \rightarrow \mathbf{1 0})$. Cross metathesis is shown to be an efficient tool to provide DML's. The cross metathesis compound $\mathbf{1 4}$ shows similar receptor affinities as its saturated analog 23 , but the weak $\mu$-agonism of the latter is changed into $\mu$ antagonism, making 14 an interesting balanced $\mu$ - $/ \delta$-antagonist.

Because of efficacy problems of naltrexone, the approved drug of choice in alcohol cessation and rapid heroin detoxification programs, ${ }^{37,38}$ balanced and general opioid antagonists have non-negligible therapeutic potential. The compact multimers 9,10 and $\mathbf{1 4}$ could serve as interesting pharmacological tools in the development of novel opioid antagonist structures with suppressed side-effects.

\section{Supplementary Material}

Refer to Web version on PubMed Central for supplementary material.

\section{Acknowledgments}

S. Ballet and D. Feytens are Research Assistants of the Fund of Scientific Research-Flanders (Belgium). This research was supported by the Australian Research Council (grant 20103228) and in part supported by the Intramural Research Program of the NIH and NIEHS. We also thank Prof. Peter Schiller (IRCM, Montreal) for the valuable comments during the preparation of this manuscript. 


\section{References}

1. Schiller PW. Life Sci. 2009 doi:10.1016/j.lfs.2009.02.025.

2. Ballet S, Pietsch M, Abell AD. Protein and Pept. Lett 2008;15:668.

3. Lipkowski AW, Konecka AM, Sroczynska I. Peptides 1982;3:697. [PubMed: 7134034]

4. Lipkowski AW, Konecka AM, Sadowski B. Pol. J.Pharmacol. Pharm 1982;34:69. [PubMed: 7167423]

5. Costa T, Wuster M, Herz A, Shimohigashi Y, Chen HC, Rodbard D. Biochem. Pharmacol 1985;34:25. [PubMed: 2981528]

6. Lipkowski AW, Konecka AM, Sroczynska I, Przewlocki R, Stala L, Tam SW. Life Sci 1987;40:2283. [PubMed: 3035308]

7. Portoghese PS, Lipkowski AW, Takemori AE. Med. Chem 1987;30:238.

8. Gao YF, Zhai MX, Liu W-X, Liu X, Yuan Y, Qi Y-M, Wang R. Protein and Pept. Lett 2008;15:275.

9. Lazarus LH, Guglietta A, Wilson WE, Irons BJ, Decastiglione R. J. Biol. Chem 1989;264:354. [PubMed: 2562839]

10. Portoghese PS, Larson DL, Yim CB, Sayre LM, Ronsisvalle G, Lipkowski AW, Takemori AE, Rice KC, Tam SW. J. Med. Chem 1985;28:1140. [PubMed: 2993609]

11. Takemori AE, Yim CB, Larson DL, Portoghese PS. Eur. J. Pharmacol 1990;186:285. [PubMed: 1963149]

12. Portoghese PS, Lipkowski AW, Takemori AE. Life Sci 1987;40:1287. [PubMed: 2882399]

13. Portoghese PS, Nagase H, Lipkowski AW, Larson DL, Takemori AE. J. Med. Chem 1988;31:836. [PubMed: 2832604]

14. Petrov RR, Vardanyan RS, Lee YS, Ma SW, Davis P, Begay LJ, Lai JY, Porreca F, Hruby VJ. Bioorg. Med. Chem. Lett 2006;16:4946. [PubMed: 16828552]

15. Lee YS, Petrov R, Park CK, Ma SW, Davis P, Lai J, Porreca F, Vardanyan R, Hruby VJ. J. Med. Chem 2007;50:5528. [PubMed: 17927164]

16. Jiang Q, Mosberg HI, Porreca F. Eur. J. Pharmacol 1990;186:137. [PubMed: 2178093]

17. Schiller PW, Weltrowska G, Berezowska I, Nguyen TMD, Wilkes BC, Lemieux C, Chung NN. Biopolymers 1999;51:411. [PubMed: 10797230]

18. Liu Z, Zhang J, Zhang A. Curr. Pharm. Des 2009;15:682. [PubMed: 19199990]

19. Marczak ED, Jinsmaa Y, Li T, Bryant SD, Tsuda Y, Okada Y, Lazarus LH. J. Pharmacol. Exp. Ther 2007;323:374. [PubMed: 17626793]

20. Weltrowska G, Lemieux C, Chung NN, Schiller PW. J. Pept. Res 2004;63:63. [PubMed: 15009527]

21. Ballet S, Salvadori S, Trapella C, Bryant SD, Jinsmaa Y, Lazarus LH, Negri L, Giannini E, Lattanzi R, Tourwé D, Balboni G. J. Med. Chem 2006;49:3990. [PubMed: 16789756]

22. Ballet S, Feytens D, De Wachter R, De Vlaeminck M, Marczak ED, Salvadori S, de Graaf C, Rognan D, Negri L, Lattanzi R, Lazarus LH, Tourwé D, Balboni G. Bioorg. Med. Chem. Lett 2009;19:433. [PubMed: 19062273]

23. Li TY, Fujita Y, Shiotani K, Miyazaki A, Tsuda Y, Ambo A, Sasaki Y, Jinsmaa Y, Marczak ED, Bryant SD, Salvadori S, Lazarus LH, Okada Y. J. Med. Chem 2005;48:8035. [PubMed: 16335927]

24. Neumeyer JL, Peng XM, Knapp BI, Bidlack JM, Lazarus LH, Salvadori S, Trapella C, Balboni G. J. Med. Chem 2006;49:5640. [PubMed: 16942040]

25. Tourwé D, Verschueren K, Frycia A, Davis P, Porreca F, Hruby VJ, Töth G, Jaspers H, Verheyden P, Van Binst G. Biopolymers 1996;38:1. [PubMed: 8679939]

26. Pulka K, Feytens D, Van den Eynde I, De Wachter R, Kosson P, Misicka A, Lipkowski A, Chung NN, Schiller PW, Tourwé D. Tetrahedron 2007;63:1459.

27. Balboni G, Trapella C, Sasaki Y, Ambo A, Marczak ED, Lazarus LH, Salvadori S. J. Med. Chem 2009;52:5556. [PubMed: 19642675]

28. Balboni G, Fiorini S, Baldiserotto A, Trapella C, Sasaki Y, Ambo A, Marczak ED, Lazarus LH, Salvadori S. J. Med. Chem 2008;51:5109. [PubMed: 18680274]

29. Cheng Y, Prusoff WH. Biochem. Pharmacol 1973;22:3099. [PubMed: 4202581]

30. Salvadori S, Balboni G, Guerrini R, Tomatis R, Bianchi C, Bryant SD, Cooper PS, Lazarus LH. J. Med. Chem 1997;40:3100. [PubMed: 9301674] 
31. Kosterlitz HW, Watt AJ. Br. J. Pharmacol 1968;33:266.

32. Salvadori S, Attila M, Balboni G, Bianchi C, Bryant SD, Crescenzi O, Guerrini R, Picone D, Tancredi T, Temussi PA, Lazarus LH. Mol. Medicine 1995;1:678.

33. Mosberg HI, Fowler CB. J. Pept. Res 2002;60:329. [PubMed: 12464111]

34. Portoghese PS. J. Med. Chem 2001;44:2259. [PubMed: 11428919]

35. Jinsmaa Y, Miyazaki A, Fujita Y, Li TY, Fujisawa Y, Shiotani K, Tsuda Y, Yokoi T, Ambo A, Sasaki Y, Bryant SD, Lazarus LH, Okada Y. J. Med. Chem 2004;47:2599. [PubMed: 15115401]

36. Vernall AJ, Ballet S, Abell AD. Tetrahedron 2008;64:3980.

37. Minozzi S, Amato L, Vecchi S, Davoli M, Kirchmayer U, Verster A. Cochrane Database Syst. Rev 2006:CD001333. [PubMed: 16437431]

38. Hall WD, Wodak A. Med. J. Australia 1999;171:9. [PubMed: 10451663] 


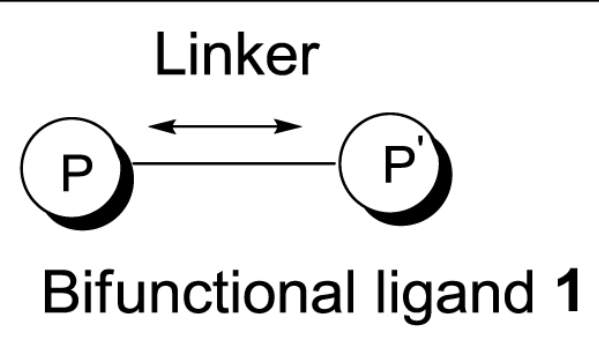

H-Tyr-D-Ala-Gly-Phe-NH-NH-Phe-Gly-D-Ala-Tyr-H 2

Enkephalin analog Enkephalin analog

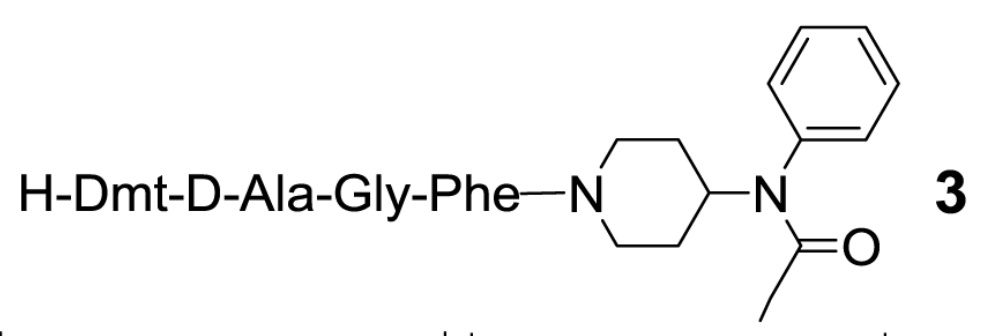

Enkephalin analog Fentanyl subunit

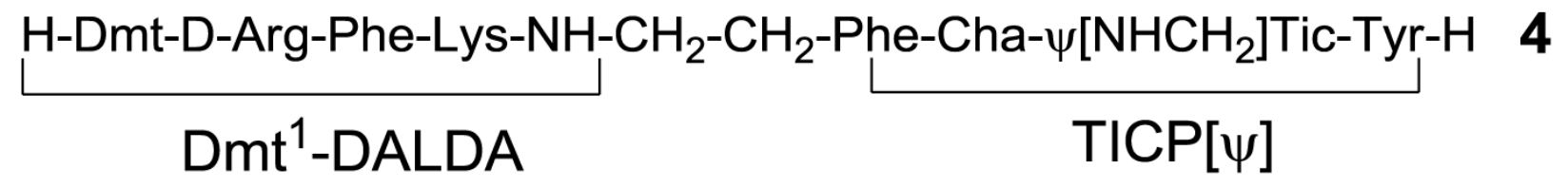

Figure 1.

General representation of bifunctional ligands 1 and literature examples 2 to 4 


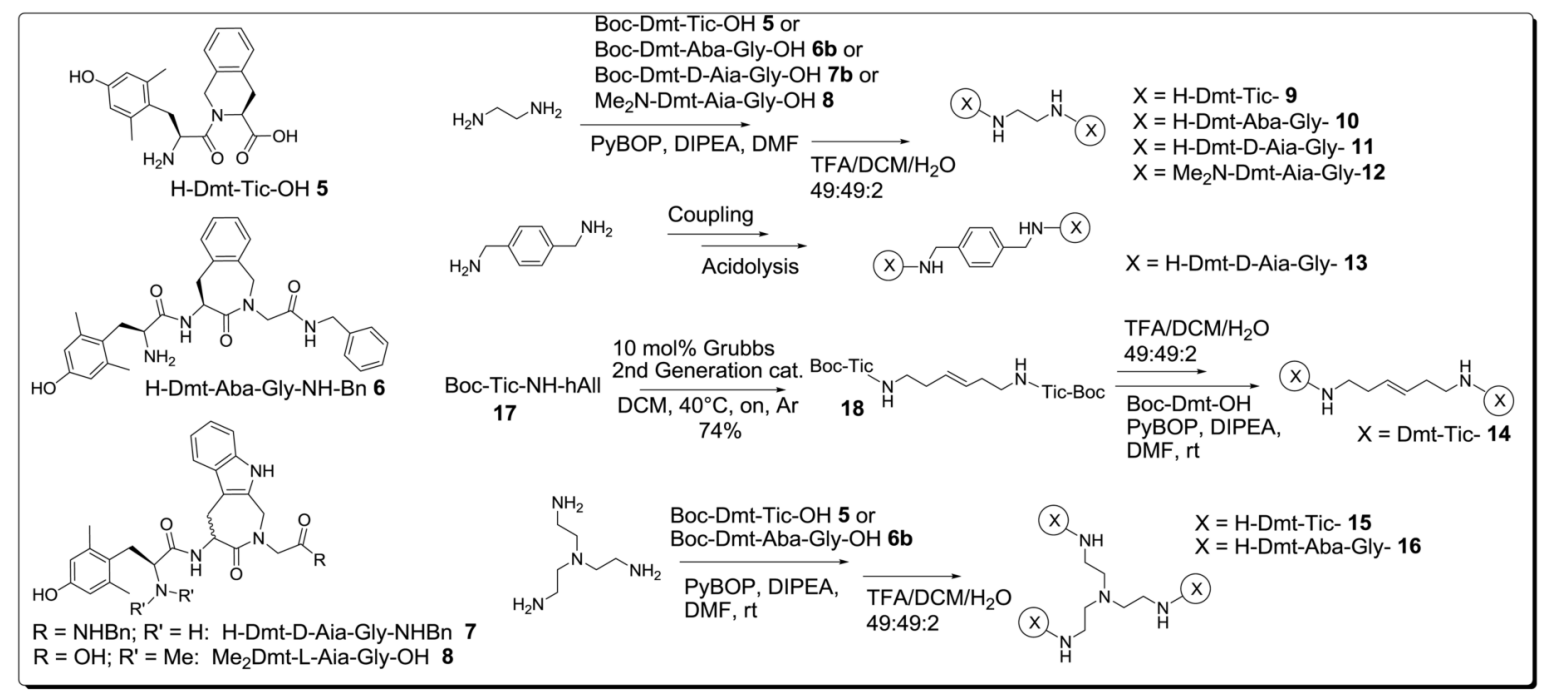

Figure 2.

Structures of H-Dmt-Tic-OH 5, H-Dmt-Aba-Gly-NH-Bn 6, H-Dmt-D-Aia-Gly-NH-Bn 7 and $\mathrm{Me}_{2}$ Dmt-L-AiaGly-OH 8 pharmacophores and synthesis of bifunctional ligands 9 to 16 


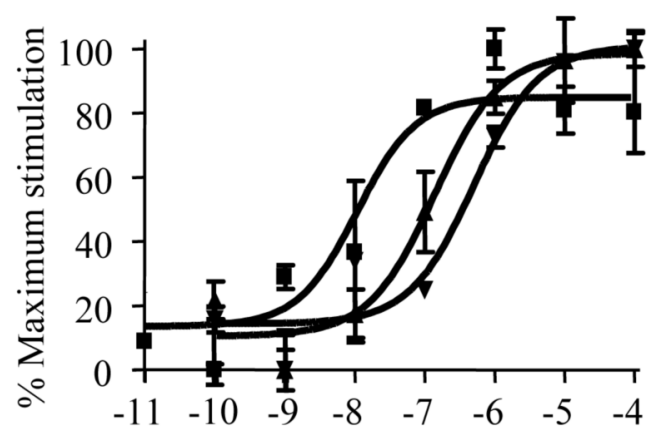

Log loperamide (M)

- Loperamide

- Lop $+9(30 \mathrm{nM})$

$\checkmark$ Lop $+9(300 \mathrm{nM})$

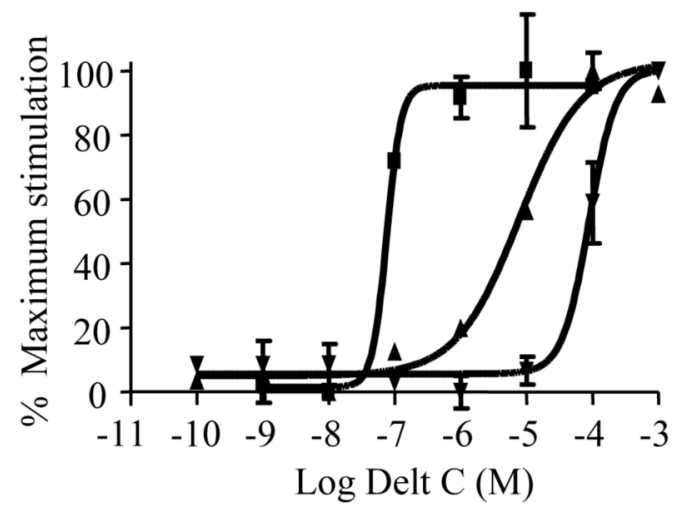

- Deltorphin C

- Delt $\mathrm{C}+9(30 \mathrm{nM})$

$\checkmark$ Delt $\mathrm{C}+\mathbf{9}(300 \mathrm{nM})$

Figure 3.

Effect of Dmt-Tic-dimer 9 on Loperamide and deltorphin C stimulated GTP $\gamma \mathrm{S}$ binding in SKN-SH and NG108-15 cell membranes, respectively. 


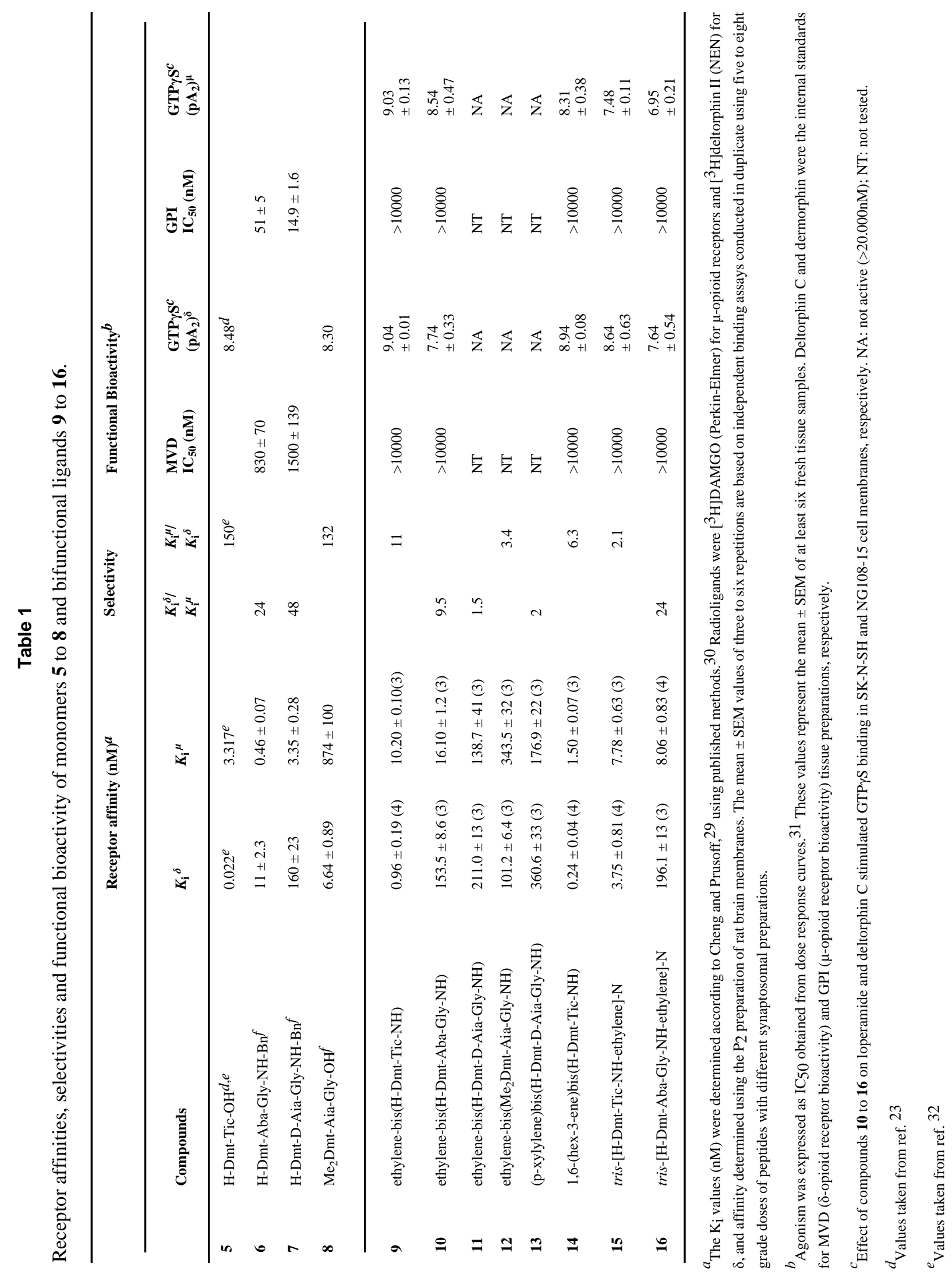


